\title{
Aspectos motivacionais na realização de atividades de voluntariado em instituição religiosa no município de Iporá (GO)
}

Faz parte da natureza humana a inclinação para viver em sociedade, bem como a necessidade de aceitação e associar-se. Assim, a vida em comunidade se expressa nas relações familiares, no clube, no trabalho, na igreja, como forma de sentir plenamente humano, agindo e vivendo solidariamente com outros seres semelhantes. Neste sentido, o voluntariado é uma atividade desenvolvida pelo indivíduo de forma espontânea e gratuita, com o propósito de ajudar outras pessoas, além de propiciar a criação de valores. Nessa perspectiva, a presente pesquisa objetivou identificar os aspectos motivacionais que influenciam a adesão e a permanência em atividades de voluntariado realizadas pela Igreja Evangélica Assembleia de Deus, no município de Iporá (GO), considerando as teorias acerca de organizações como sistemas sociais e motivação humana. Acerca disso, a pesquisa é considerada qualitativa, quanto à sua natureza, e possui caráter exploratório, tendo sido realizada por meio da aplicação de questionário misto junto aos voluntários, de modo a detectar os aspectos motivacionais que influenciam a adesão e a permanência nas atividades de voluntariado. Conclui-se, portanto, que os voluntários exercem esse tipo de trabalho motivados pela compaixão com o indivíduo, a fim de buscar a transformação desse sujeito. Enfim, os objetivos foram alcançados no que se refere aos aspectos motivacionais humanos explanados nas abordagens teóricas.

Palavras-chave: Motivação; Recursos humanos; Trabalho.

\section{Motivational aspects in performing volunteer activities in a religious institution in the city of Iporá (GO)}

\begin{abstract}
Part of human nature is the inclination to live in society, as well as the need for acceptance and association. Thus, life in community is expressed in family relationships, in the club, at work, in the church, as a way of feeling fully human, acting and living in solidarity with other similar beings. In this sense, volunteering is an activity developed by the individual spontaneously and free of charge, with the purpose of helping other people, as well as promoting the creation of values. From this perspective, this research aimed to identify the motivational aspects that influence the adherence and permanence in volunteer activities carried out by the Evangelical Church Assembly of God, in the city of Iporá (GO), considering the theories about organizations such as social systems and human motivation. In this regard, the research is considered qualitative in nature, and is exploratory in nature, having been conducted through the application of a mixed questionnaire to the volunteers, in order to detect the motivational aspects that influence adherence and permanence in the activities of children. volunteering. It is concluded, therefore, that volunteers perform this type of work motivated by compassion with the individual, in order to seek the transformation of this subject. Finally, the objectives were achieved regarding the human motivational aspects explained in the theoretical approaches.
\end{abstract}

Keywords: Motivation; Human Resources; Job.

\section{Topic: Recursos Humanos}

Reviewed anonymously in the process of blind peer.
Received: 03/02/2019

Approved: 02/05/2019
Maria Gláucia Dourado Furquim (ib)

Instituto Federal Goiano, Brasil

http://lattes.cnpq.br/2681775689273863

http://orcid.org/0000-0001-7823-9546

maria.furquim@ifgoiano.edu.br

Neusimar Vargas Pinheiro Oliveira

Instituto Federal Goiano, Brasil

http://lattes.cnpq.br/4653147427903492

jcsj10@gmail.com

Carolina Bernardes Santos

Instituto Federal Goiano, Brasil

http://lattes.cnpq.br/4718748089358178

icsj10@gmail.com

\author{
José Carlos de Sousa Júnior (iD \\ Instituto Federal Goiano, Brasil \\ http://lattes.cnpq.br/9146562480275155 \\ http://orcid.org/0000-0003-2578-8140 \\ josecarlos.junior@ifgoiano.edu.br \\ João Gabriel Taveira Silva \\ Instituto Federal Goiano, Brasil \\ http://lattes.cnpq.br/9080090067805440 \\ icsj10@gmail.com
}

Referencing this:

FURQUIM, M. G. D.; OLIVEIRAM N. V. P.; SANTOS, C. B.; SOUSA JÚNIOR, J. C.; SILVA, J. G. T.. Aspectos motivacionais na realização de atividades de voluntariado em instituição religiosa no município de Iporá (GO). Entrepreneurship, v.3, n.1, p.9-18, 2019. DOI: http://doi.org/10.6008/CBPC2595-4318.2019.001.0002 


\section{INTRODUÇÃO}

O trabalho voluntário consiste em atividades desenvolvidas pelo indivíduo de forma espontânea e gratuita, com o propósito de ajudar outras pessoas. É regido pela Lei no $13.297 / 2016$, que estabelece os critérios que norteiam as ações de voluntariado, definido conforme Art. 1ㅇ: 'Considera-se serviço voluntário, para os fins desta Lei, a atividade não remunerada prestada por pessoa física a entidade pública de qualquer natureza ou a instituição privada de fins não lucrativos que tenha objetivos cívicos, culturais, educacionais, científicos, recreativos ou de assistência à pessoa'. Com o desenvolvimento do trabalho voluntário e social, dá-se a oportunidade, aos diversos trabalhadores, de desempenhar seus talentos. Desse modo, cada voluntário escolhe dedicar e conciliar o tempo de prestação do serviço sem prejudicar seus demais afazeres.

O voluntário, além de exercer sua atividade colaborativa, adquire experiências, constrói amizades, além de poder dialogar com novas pessoas, demonstrando o caráter, a confiança e a personalidade. Neste estudo, observa-se o desenvolvimento desta atividade na Igreja Evangélica Assembleia de Deus de Iporá, no estado de Goiás, que tem seu campo de abrangência composto pelos seguintes municípios: Ivolândia, Moiporá, Israelândia, Diorama, Jaupaci e Amorinópolis.

Preocupada com o campo Missionário, essa instituição tem, em seus registros, congregações no estado do Piauí, além de manter instituições beneficentes agregadas. Dentre as ações desenvolvidas, destaca-se o trabalho voluntário de irmãos e de simpatizantes que abdicaram de seu tempo e de seus afazeres seculares para então, movidos pelo desejo de ver acontecer mudanças notáveis no meio da sociedade, visando o bem-estar do próximo e, em especial das famílias das viúvas, realizarem mutirões para a construção da casa dessas viúvas, sendo elas as assistidas pelo trabalho da Confederação das Irmãs Beneficentes Evangélicas CIBEI (GOMIS, 2012).

A fim de atender aos anseios de diversos participantes surgiram outros projetos, como os trabalhos da Tarde da Vitória e da Clínica da Alma, ambos os trabalhados realizados todas as quartas e quintas-feiras por pessoas dedicadas ao trabalho voluntário, dentre elas profissionais de psicologia, pastores, intercessores, conselheiros e recepcionistas. $O$ trabalho feito pela Clínica da Alma também disponibiliza o atendimento por telefone, e se tem a Tarde da Vitória, que realiza atendimento espiritual.

O trabalho social busca incluir o cidadão nas diversas atividades, levando-o a desenvolver, ao longo do tempo, suas habilidades. Na Igreja Evangélica Assembleia de Deus, na cidade de Iporá, já é notório este trabalho realizado por diversos colaboradores e vocacionados, independente do grau de escolaridade. Cada (voluntário) profissional pode desenvolver a atividade com a qual possui mais afinidade e se sinta melhor, mostrando novas habilidades para lidar com diferentes realidades, superar dificuldades, encontrar soluções, se relacionar com outras pessoas.

O trabalho voluntário traz benefícios para a sociedade, vez que, diante das ações espontaneamente realizadas, alcançam-se resultados de transformação individual ou coletiva. Nesse sentido, considerando o conceito de organização como sistema social, emerge a preocupação com a coletividade e a efetiva participação de cada indivíduo para que isso aconteça, conforme Chiavenato (2009), "[a] vida das pessoas 
constitui uma infinidade de interações com outras pessoas e com organizações. O ser humano é eminentemente social e interativo. Não vive isoladamente, mas em constante convívio e relacionamento com semelhantes".

Nesse sentido, o objetivo desta pesquisa é identificar os aspectos motivacionais que influenciam a adesão e a permanência em atividades de voluntariado realizadas pela Igreja Evangélica Assembleia de Deus, com enfoque para as atividades ocorridas especificamente no município de Iporá, nos dias de quarta-feira e quinta-feira, tendo a Gestão de Pessoas e as respectivas abordagens teóricas acerca de motivação humana como parâmetro para fomentar/manter o trabalho voluntário na organização analisada.

\section{REVISÃO TEÓRICA}

\section{Motivação humana nas organizações: abordagem conceitual}

O processo de transformação das relações humanas nos diversos ambientes sociais, em consonância com as contribuições das diversas áreas do conhecimento - como Sociologia, Psicologia e Antropologia -, concederam aos gestores nas organizações, nas últimas décadas, as respostas de certas lacunas sobre a pessoa como pessoa e os respectivos aspectos interiores que movem o colaborador em seu ambiente externo. "O ambiente de trabalho moderno é, para dizer o mínimo, desafiador. O sucesso das organizações e das pessoas que as fazem funcionar não vem fácil. Essa era de contrastes abre a porta para a criatividade na administração" (KLAVA, 2010).

Nessa perspectiva, o fator econômico das pessoas nas organizações é percebido quando o colaborador trabalha com satisfação, o que, consequentemente, afeta os resultados. Assim, a motivação consiste no processo responsável por impulsionar o comportamento do indivíduo para determinada ação. De acordo com Chiavenato (2004), "Os seres humanos são motivados por uma grande variedade de fatores. O processo motivacional pode ser explicado da seguinte forma: as necessidades e carências provocam tensão e desconforto na pessoa e desencadeiam um processo que busca reduzir ou eliminar a tensão".

Segundo Robbins (2005), a motivação possui três vertentes: direção; foco da pessoa em sua meta e como realizar; e o respectivo grau de satisfação decorrente do alcance do objetivo. Para Maximiano (2007), “[a] motivação é específica. Uma pessoa motivada para trabalhar pode não ter motivação para estudar ou vice-versa. Não há um estado geral de motivação, que leve uma pessoa a sempre ter disposição para tudo." Assim, a motivação humana é uma importante ferramenta para promover o sucesso organizacional, pois afeta diretamente o desempenho funcional do colaborador. Dentre as teorias motivacionais destacam-se a pirâmide das necessidades, de Maslow, e a dos dois fatores, de Herzberg.

Maslow divide as necessidades dos indivíduos em cinco partes e dois grupos, conforme a importância que se dá para cada necessidade, e os níveis vão sendo ultrapassados. Esses fatores estão organizados e dispostos em níveis, numa hierarquia de importância e influências. Essa hierarquia de necessidades é representada e visualizada em uma pirâmide, cuja base está no patamar das necessidades mais baixas e no topo estão as mais elevadas (figura 1). 


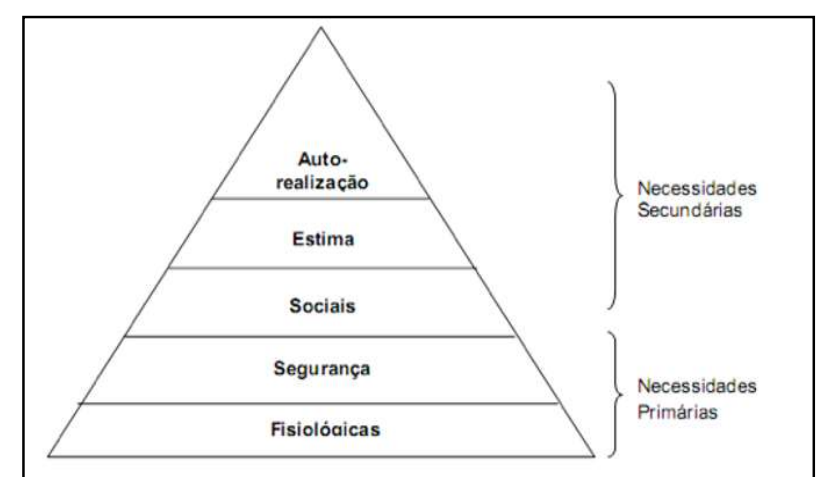

Figura 1: Pirâmide das necessidades de Maslow. Fonte: Chiavenato (2009).

Nesse sentido, os cinco níveis a serem 'escalados' por um ser humano, segundo Maslow, são: Necessidades fisiológicas: são aquelas relacionadas ao ser humano como ser biológico. Constitui o nível mais baixo na hierarquia e são as mais importantes: necessidades de manter-se vivo, de respirar, de comer, de descansar, beber, dormir, ter relações sexuais, etc.; Necessidades de segurança: referem-se a questões vinculadas às necessidades de sentir-se seguro e de proteger-se contra riscos reais e potenciais: sem perigo, em ordem, com segurança, de conservar o emprego, etc. No trabalho: emprego estável, plano de saúde, seguro de vida, etc..

Além desses, têm-se: Necessidades sociais: são aquelas que remetem à vida associativa e ao desejo de aceitação nas relações humanas: sentir-se parte de um grupo, ser membro de um clube, receber carinho e afeto dos familiares, amigos e pessoas do sexo oposto; Necessidades de estima: dividem-se em dois tipos: o reconhecimento das nossas capacidades por nós mesmos e o reconhecimento dos outros da nossa capacidade de adequação. Em geral, é a necessidade de sentir-se digno, respeitado por si e pelos outros, com prestígio e reconhecimento, poder, orgulho, etc. Incluem-se também as necessidades de autoestima; e Necessidades de autorrealização: encontram-se no topo das necessidades e consistem no próprio crescimento do indivíduo. Incluem a realização, aproveitar todo o potencial próprio, ser aquilo que se pode ser, fazer o que a pessoa gosta e é capaz de conseguir.

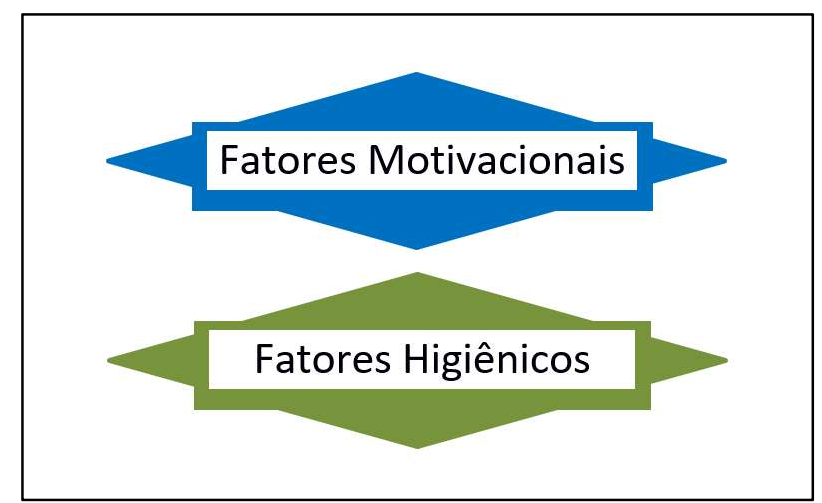

Figura 2: A teoria dos dois fatores de Herzberg. Fonte: Chiavenato (2002).

Por sua vez, para Herzberg (1973, citado por CHIAVENATO, 2002), dois fatores vão condicionar a motivação das pessoas para o trabalho, sendo eles os higiênicos, que correspondem ao contexto do trabalho, e os motivacionais, que dizem respeito ao cargo, às tarefas e às atividades relacionadas com o cargo. Herzberg (1973, citado por CHIAVENATO, 2002) finaliza que "enquanto Maslow fundamenta a sua teoria da 
motivação nas diferentes necessidades humanas [...] intra-orientada, Herzberg alicerça sua teoria no ambiente externo e no trabalho do indivíduo [...]". Assim, os fatores que motivam e desestimulam na situação de trabalho são os motivacionais e o higiênico e este último, por sua vez, "[...] não conseguem elevar substancial e duradouramente a satisfação" (CHIAVENATO, 2002), conforme ilustra a figura 2.

Herzberg concluiu que existe dois tipos de necessidades independentes entre si e que influenciam o trabalho dos funcionários de vários modos. 0 primeiro tipo, os fatores de higiene, ocorrem quando a empresa em si deixa os profissionais insatisfeitos. Já o segundo tipo, os motivacionais, acontecem quando os profissionais se sentem desafiados e estão genuinamente interessados.

Os fatores de higiene são aspectos relacionados ao ambiente em que o colaborador trabalha, envolvem a política e a administração da empresa, a supervisão, as condições de trabalho, as relações interpessoais, o dinheiro, o status e a segurança, correlacionando-os com prevenção e a área ambiental, por reduzir perdas no desempenho por causa de restrições. Já os Fatores motivadores envolvem o sentimento de realização, de crescimento profissional e de reconhecimento no trabalho. Herzberg usou esse termo porque esses fatores pareciam ser capazes de ter um efeito positivo sobre a satisfação no trabalho.

\section{Trabalho voluntário: fonte de realização pessoal}

Diferentemente das particularidades presentes no mercado de trabalho e de recursos humanos para a alocação do indivíduo (situações de oferta e de demanda), o trabalho voluntário depende exclusivamente da disponibilidade da pessoa em realizar determinada ação. Como o próprio nome remete, compreende um trabalho sem remuneração, onde o voluntariado dedica seu tempo a ajudar outras pessoas com atividades em diversas áreas, tais como hospitalar, creches, asilos, etc.. Outro ponto importante e que o faz diferir das atividades padronizadas desenvolvidas é a ausência de critérios fixos para atuar como voluntário, não necessitando de determinado grau de escolaridade ou idade, e sim de responsabilidade com a área de interesse. Cabe à pessoa escolher no que quer ajudar.

A Lei no 13.297, de 16 de junho de 2016, alterou o art. 1ㅇda Lei nำ.608, de 18 de fevereiro de 1998, para incluir a assistência à pessoa como objetivo da atividade não remunerada reconhecida como serviço voluntário. A nova redação estabelece: ‘Considera-se serviço voluntário, para os fins desta Lei, a atividade não remunerada prestada por pessoa física a entidade pública de qualquer natureza ou a instituição privada de fins não lucrativos que tenha objetivos cívicos, culturais, educacionais, científicos, recreativos ou de assistência à pessoa'. Em seu parágrafo único, explica que o '[...] serviço voluntário não gera vínculo empregatício, nem obrigação de natureza trabalhista previdenciária ou afim'.

São vários os motivos que levam a pessoa a querer praticar essa ação - seja religioso, político ou social - em favor daqueles que necessitam. Também existem diferenças no grau de comprometimento no trabalho voluntário: alguns podem praticá-lo esporadicamente e sentirem que fizeram a sua parte; outros podem tratá-lo como uma rotina.

O voluntariado, fruto das ações do voluntário, é o conjunto de atividades de interesse social em âmbito local em que toda a atividade desempenhada se reverte a favor do serviço e do trabalho com 
objetivos específicos para a coletividade. É uma profissão de prestígio social, visto que o voluntário ajuda a quem precisa, contribuindo para um mundo mais justo e mais solidário.

\section{METODOLOGIA}

O estudo da teoria foi desenvolvido com a utilização de fontes diversas - livros, artigos científicos e periódicos - pertinentes aos temas organizações como sistemas sociais, motivação humana e trabalho voluntário, atribuindo um caráter exploratório à pesquisa. A pesquisa foi realizada na Igreja Evangélica Assembleia de Deus (sede) de Iporá, município do estado de Goiás, onde foram identificados os projetos desenvolvidos por voluntários na organização e, posteriormente, detectados os aspectos motivacionais que influenciam a adesão e a permanência desses indivíduos nas ações.

Para tanto, foi elaborado um questionário misto com dez questões e aplicado aos membros voluntários da instituição totalizando 36 respondentes, o que corresponde a uma amostra de 100 da população (voluntários atuantes na Tarde da Vitória e da Clínica da Alma), sendo, portanto, uma amostra por conveniência. Os questionários foram aplicados durante o mês de março/2018 e os dados foram processados em abril-maio/2018 através do programa Excel for Windows.

Segundo Gil (2002), o questionário pode ser definido como "[...] um instrumento de investigação que visa recolher informações baseando-se, geralmente, na inquisição de um grupo representativo da população em estudo". O tipo de questionário adotado é tal como o nome indica, ou seja, apresenta questões com diferentes tipos de respostas, podendo elas serem abertas (permitem ao inquirido construir a resposta com as suas próprias palavras, propiciando a liberdade de expressão) e/ou fechadas (são aquelas nas quais o inquirido apenas seleciona a opção, dentre as apresentadas, que mais se adéqua à sua opinião).

A pesquisa se caracteriza como qualitativa, na qual "o cientista objetiva aprofundar-se na compreensão dos fenômenos que estuda - ações dos indivíduos, grupos ou organizações em seu ambiente ou contexto social -, interpretando-os segundo a perspectiva dos próprios sujeitos que participam da situação" (GUERRA, 2014).

A Igreja Assembleia de Deus de Iporá, município localizado na microrregião de Iporá, na região Centro-Oeste do estado de Goiás, e em seus 61 anos de existência, e desde o início da sua fundação, especificamente na cidade de Iporá - depois da organização da igreja no Buriti, em 9 de abril de 1944 - e até o momento presente, contou com nove obreiros/pastor presidente. A jurisdição da Assembleia de Deus de Iporá abrange, além dessa cidade, os municípios vizinhos de Ivolândia, Moiporá, Israelândia, Jaupaci, Diorama, Montes Claros de Goiás, Amorinópolis, e os de Floriano e Canto do Buriti, no Piauí. Conta, atualmente, com trinta congregações e dez subcongregações filiadas, num total de 41 igrejas. Seu quadro de obreiros está constituído de 23 pastores, 82 evangelistas, 185 presbíteros, 223 diáconos, 124 diaconisas e 15 missionárias.

Mantém uma instituição beneficente, o Lar Bom Samaritano, que abriga trinta internos, de ambos os sexos, incluindo idosos e deficientes e a Casa das Viúvas, um grande barracão com pequenos apartamentos, onde várias senhoras idosas vivem independentes e sustentadas pela igreja, através da gestão da 
Confederação das Irmãs Beneficentes Evangélicas (Cibe), que presta, ainda, assistência social a dezenas de famílias carentes, com cestas básicas, medicamentos e outros benefícios materiais. Além dessas ações, conta também com educação religiosa, realizada por meio da Escola Dominical, e trabalhos da Tarde da Vitória e da Clínica da Alma, sendo todas as atividades desenvolvidas por voluntários.

\section{RESULTADOS E DISCUSSÃO}

Conforme Chiavenato (2009) “Devido a suas limitações individuais, os seres humanos são obrigados a cooperarem uns com os outros, formando organizações para alcançar certos objetivos que a ação individual isolada não conseguiria alcançar". Para Tachizawa et al. (2001), a gestão de pessoas está presente em todos os processos de uma organização, seja ela com ou sem fins lucrativos, sendo desenvolvido por pessoas cujas atitudes, conhecimentos e comportamentos são variáveis de desempenho importante que influenciam o trabalho.

Para Aristóteles, a sociabilidade configura a própria essência do homem, não alcançando a autorrealização sem a formação de vínculos sociais para satisfazer suas necessidades, carências e limitações. Diante deste contexto, buscou-se, inicialmente, traçar o perfil dos voluntários da instituição analisada, sendo apresentado no gráfico 1 o número de voluntários em relação ao sexo. Dos 36 entrevistados, 23 são do sexo feminino e 13 são pertencentes ao sexo masculino. Há, então, uma maior representatividade do sexo feminino no desenvolvimento do trabalho voluntário.

No que diz respeito à faixa etária dos entrevistados que exercem o trabalho voluntariado, conforme apresenta o Gráfico 2, 19 voluntários possuem idade superior a 50 anos, 7 voluntários possuem idade entre 41 a 50 anos, e apenas 9 voluntários com idade entre 18 a 40 anos. Logo, observa-se que o quantitativo de pessoas voluntárias é em sua maioria com idade superior a 50 anos.

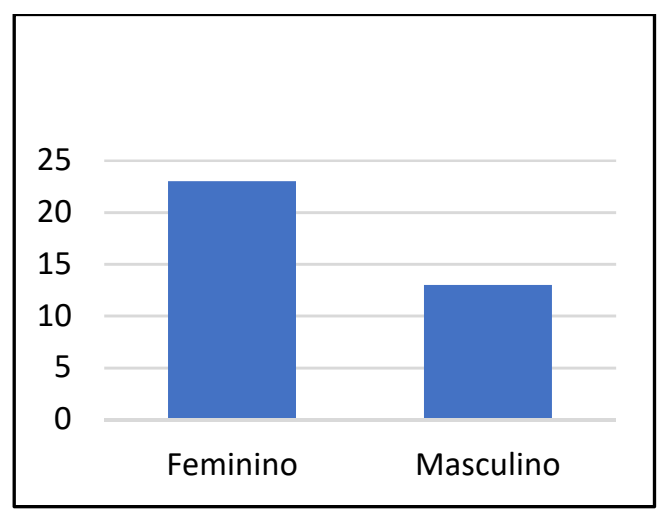

Gráfico 1: Número de voluntários em relação ao sexo.

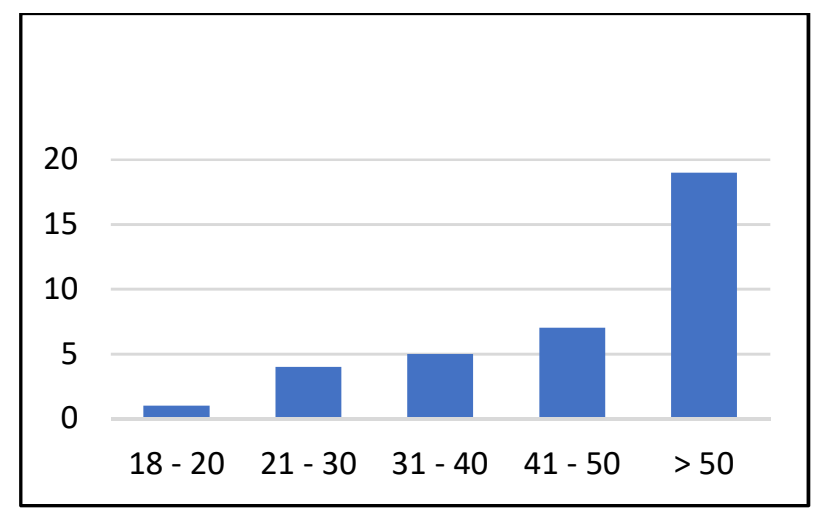

Gráfico 2: Faixa etária (anos) dos voluntários.

No que se refere ao nível de escolaridade dos voluntários, diagnosticou-se que a maioria possui o ensino médio completo (33\%), conforme demonstra o gráfico 3 . Se for somarmos o percentual que ingressaram ou mesmo concluíram um curso superior o percentual é de $(42 \%)$, representando que são pessoas com elevados grau de escolaridade e que optaram pelo 'se doar' ao próximo como forma de contribuição para com a sociedade. Observa-se que, $28 \%$ dos colaboradores possui ensino superior completo, $14 \%$ dos voluntários (superior incompleto), $14 \%$ e $11 \%$ dos colaboradores responderam, 
respectivamente, que possuem o ensino médio incompleto e fundamental completo, de acordo com o gráfico 3.

Quando questionados sobre qual atividade de voluntariado realiza, obteve-se que, $66,67 \%$ são intercessores, 13,89\% exercem a atividade de auxiliar/recepção, psicólogo (8,33\%), respectivamente 2,78\% responderam que exercem atividade de coordenador/intercessor e pastor dirigente, conforme descrito no gráfico 4. Quanto à frequência em que participa das atividades de voluntariado, observou-se, que 19 pessoas participam da Tarde da Vitória no período vespertino, visto que esta é realizada somente no período vespertino. Já a Clínica da Alma, 14 voluntários participam o dia todo, 3 participam respectivamente, no período vespertino e a cada 15 dias, 2 pessoas (matutino), conforme apresenta o gráfico 5 .

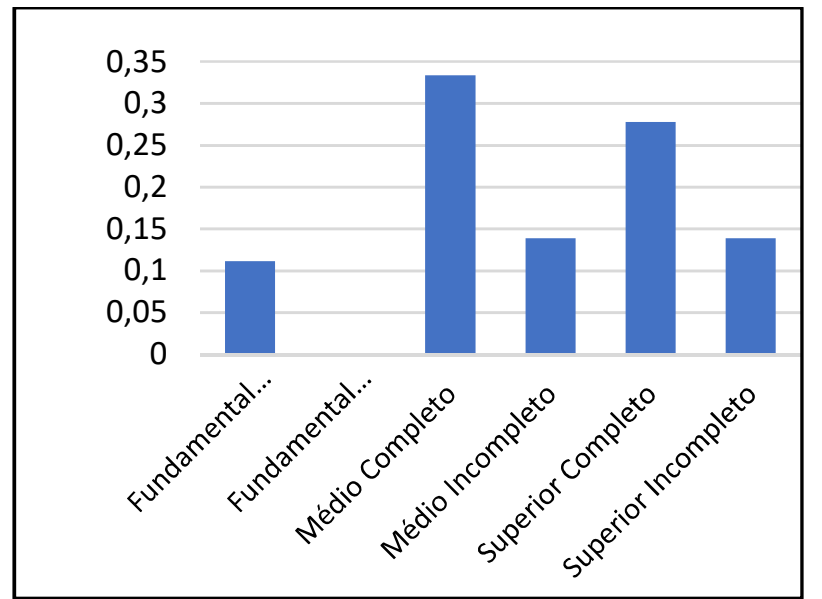

Gráfico 3: Nível de escolaridade dos voluntários em (\%).

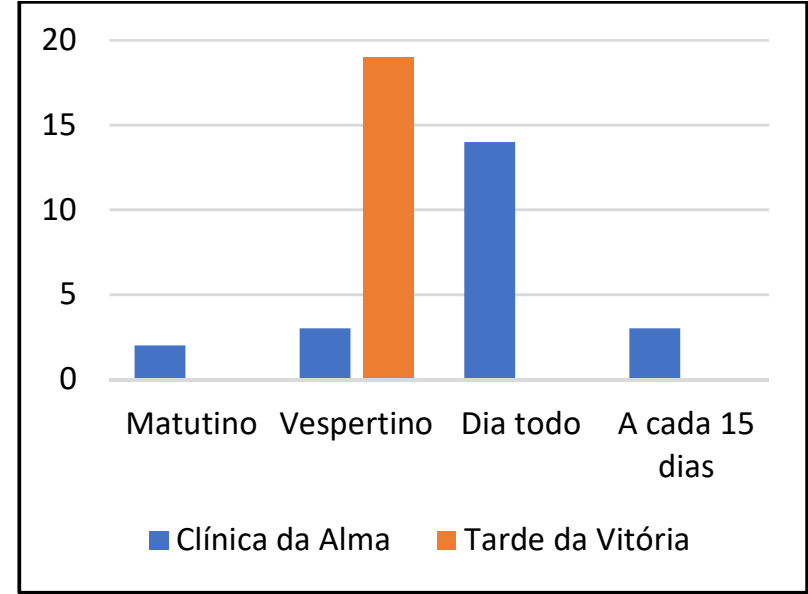

Gráfico 5: Frequência com que participa das atividades, dia e horário?.

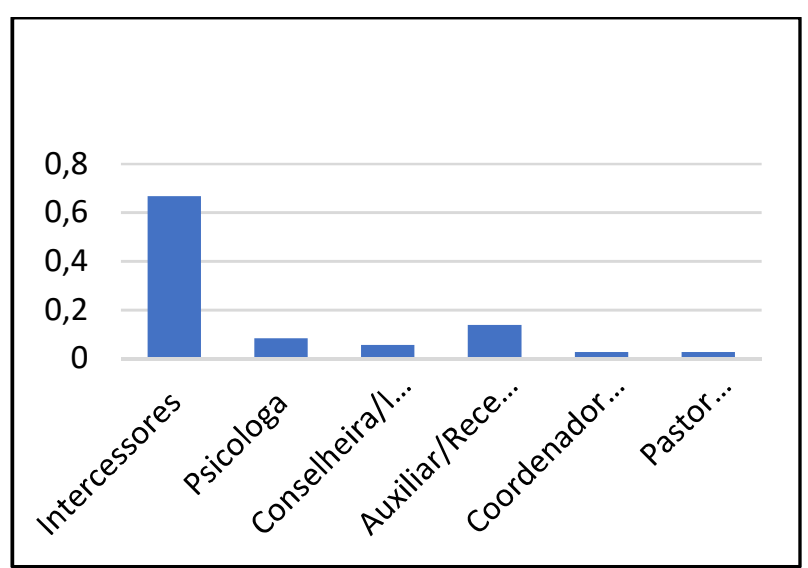

Gráfico 4: Atividades realizadas pelos voluntários em (\%).

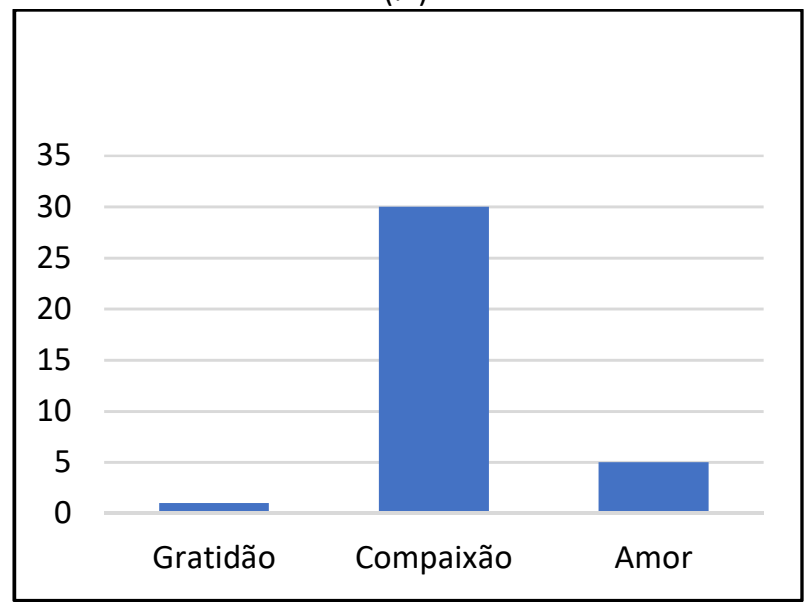

Gráfico 6: Motivação para participar da atividade de voluntariado.

No que se refere à motivação que levou os entrevistados a realizar atividades dessa natureza, 30 voluntários responderam que foi devido à compaixão, 5 por amor e 1 por gratidão. Nota-se que o 'querer bem' e o 'se doar' são fortes valores que impulsionam o desempenho de atividades dessa natureza. Herzberg (1973) afirma que "os fatores motivadores tornam as pessoas felizes com os seus serviços porque atendem a necessidade básica e humana de crescimento psicológico; uma necessidade de se tornar mais competente". 


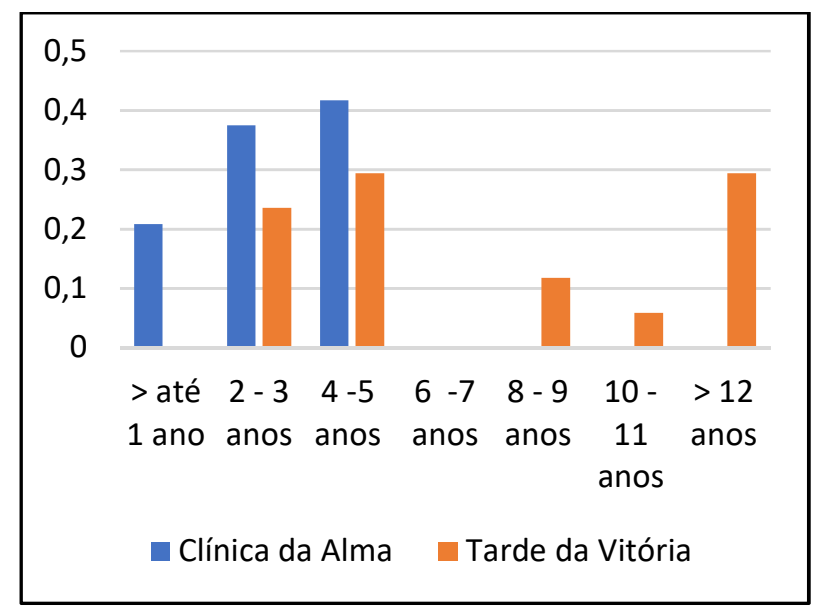

Gráfico 7: Período (anos) que participa das atividades propostas.

Conforme descrito no gráfico 7, 42\% dos voluntários que participam da Clínica da alma responderam que exercem o trabalho voluntário de 4 a 5 anos, 38\% de 2 a 3 anos e $21 \%$ até 1 ano. Já os voluntários que participam da Tarde da Vitória relataram que 29\% participam respectivamente há acima de 12 anos e de 4 a 5 anos, 24\% de 2 a 3 anos, 8 a 9 anos (12\%), e de 10 a 11 anos (6\%). Observa-se que, os voluntários da Tarde da Vitória, já exercem o trabalho a maior tempo. Dentre os principais desafios relatados pelos entrevistados estão o exercício das atividades diárias (42\%), apesar de $28 \%$ relatarem que não possuem nenhum impedimento. Outros desafios citados são saúde/cirúrgico (8\%) e dificuldades quanto à locomoção, atendimento ao público e cansaço (6\%). Por ser uma atividade desempenhada, em sua maioria, por mulheres, os afazeres domésticos tornam-se um impeditivo para a realização das atividades de voluntariado.

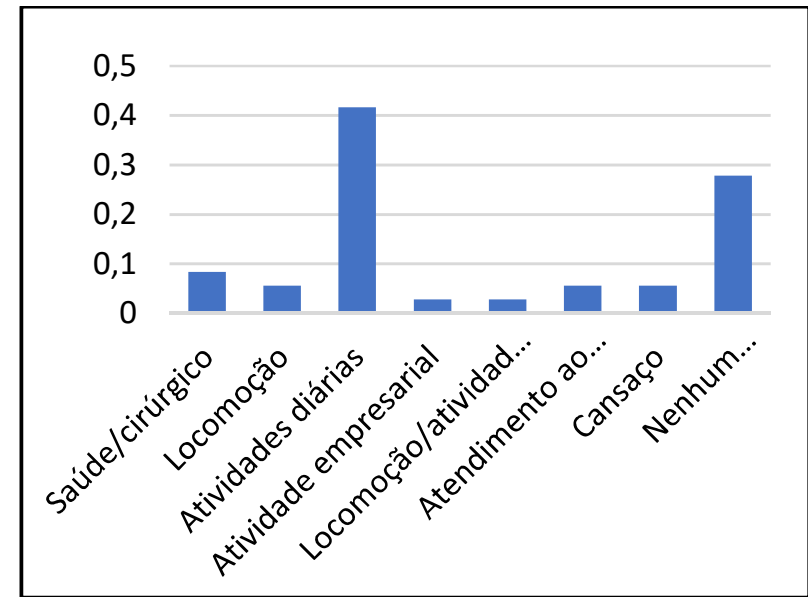

Gráfico 8: Desafios enfrentados para a realização das atividades de voluntariado em (\%).

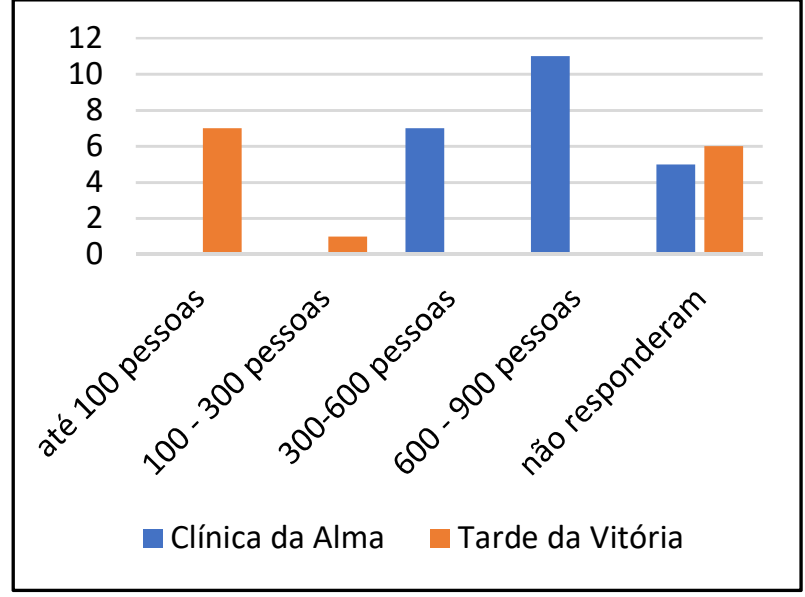

Gráfico 1: Número de pessoas beneficiadas por estas ações.

Com relação ao número de pessoas beneficiadas mensalmente por essas ações, 11 voluntários entrevistados consideram que a Clínica da Alma atende entre 600 e 900 pessoas, 7 consideram que atende de 300 a 600 pessoas e 7 não responderam. Já com relação à Tarde da Vitória, 7 voluntários responderam que até 100 pessoas são atendidas, 6 voluntários não responderam e 1 deles disse que são de 100 a 300 pessoas. Devido à sobrecarga de trabalho, ao uso intensivo de tecnologias e mídias sociais, além do próprio relacionamento interpessoal, são fatores que desencadeiam nos indivíduos distúrbios e depressões, os quais 
os leva a procurar ajudar. Esse fato justifica o elevado atendimento de pessoas. Quando questionados sobre quais as perspectivas em termos de ações de voluntariado, obteve-se que a pretensão é transformar os indivíduos atendidos, buscando a mudança e a diminuição do sofrimento, assim como reestruturar lares e alcançar a espiritualidade.

\section{CONSIDERAÇÕES FINAIS}

O voluntariado é algo desenvolvido a partir de diversas motivações, e sabe-se que a motivação humana é uma ação intrínseca, vem de dentro do indivíduo, sendo diversos os fatores que os motivam: financeiro, satisfação pessoal ou até mesmo a influência na comunidade. Vilela (2010) relata a motivação humana como uma força intrínseca, ou seja, esse processo ocorre de dentro para fora do indivíduo, e não o contrário; quando essa ação ocorre de fora para dentro do indivíduo é chamada de incentivo ou estímulo.

Portanto, a partir dos resultados obtidos pelo presente estudo, evidencia-se que o trabalho voluntário desenvolvido pelos entrevistados é motivado pela compaixão com o indivíduo, a fim de buscar a transformação deste. Nota-se que são atividades duradouras, cujos principais gargalos enfrentados estão relacionados com o desempenho das atividades diárias, em especial das mulheres, que tem nos afazeres domésticos um impeditivo para a realização das atividades de voluntariado. 0 presente trabalho pretende ser uma ferramenta de auxílio para futuros trabalhos sobre a temática abordada, haja vista que, há poucos estudos com este enfoque. Notavelmente, o desempenho da atividade de voluntariado propicia ao indivíduo apoio mútuo ou recíproco entre os agentes envolvidos.

\section{REFERÊNCIAS}

BRASIL. Lei n.13297 de 16 de junho de 2016. Dispõe sobre o serviço voluntário e dá outras providências. Brasília: DOU, 2016.

CHIAVENATO, I.. Gestão de pessoas e o novo papel dos recursos humanos nas organizações. 2 ed. Rio de Janeiro: Elsevier, 2004.

CHIAVENATO, I.. Recursos humanos. 7 ed. São Paulo: Atlas, 2002.

CHIAVENATO, I.. Recursos humanos: o capital humano das organizações. 8 ed. Rio de Janeiro: Elsevier, 2009.

GIL, A. C.. Como elaborar projetos de pesquisa. 4 ed. São Paulo: Atlas, 2002.

GOMIS, M. A.. Quando Samambaia pegou fogo. Goiânia: Kelps, 2012.

GUERRA, E. L. A.. Manual pesquisa qualitativa. Belo Horizonte: 2014.
HERZBERG, F.. O conceito de higiene como motivação e os problemas do potencial humano no trabalho. In: HAMPTON, D. R.. Conceitos de comportamento na administração. São Paulo: EPU, 1973. p.53-62.

KLAVA, V.. Motivação empresarial: o desafio do século XXI. São Paulo: 2010

MAXIMIANO, A. C. A.. Teoria Geral da Administração: da revolução urbana a revolução digital. 6 ed. São Paulo: Atlas, 2007.

ROBBINS, S. P.. Comportamento organizacional. 11 ed. São Paulo: Pearson Prentice Hall, 2005.

TACHIZAWA, T.; FERREIRA, V. C. P.; FORTUNA, A. A. M. Gestão com pessoas: uma abordagem aplicada às estratégias de negócios. 2 ed. Rio de Janeiro: FGV, 2001.

VILELA, A. V.. A importância da motivação e sua influência no ambiente de trabalho. Monografia (Especialização) Universidade Cândido Mendes, Rio de Janeiro, 2010.

A CBPC - Companhia Brasileira de Produção Científica (CNPJ: 11.221.422/0001-03) detém os direitos materiais desta publicação. Os direitos referem-se à publicação do trabalho em qualquer parte do mundo, incluindo os direitos às renovações, expansões e disseminações da contribuição, bem como outros direitos subsidiários. Todos os trabalhos publicados eletronicamente poderão posteriormente ser publicados em coletâneas impressas sob coordenação da Sustenere Publishing, da Companhia Brasileira de Produção Científica e seus parceiros autorizados. Os (as) autores (as) preservam os direitos autorais, mas não têm permissão para a publicação da contribuição em outro meio, impresso ou digital, em português ou em tradução. 